\title{
Relationships between Learning Styles, Perceived Advantages of Online Collaborative Learning and Practical Knowledge in Teaching among Taiwanese Student Teachers
}

\author{
Shih-Hsiung Liu ${ }^{1}$ \\ ${ }^{1}$ Center for Teacher Education, National Changhua University of Education, Taiwan \\ Correspondence: Shih-Hsiung Liu. Tel: 886-4-723-2105. E-mail: shsiung@cc.ncue.edu.tw
}

Received: August 8, 2017

doi:10.5539/ass.v13n11p34

\begin{abstract}
The purpose of this study is to investigate the effects of the three learning styles (collaborative, competitive, and individualistic) on the perceived advantage of collaborative learning (PAoCL) and practical knowledge in teaching (PKiT) among Taiwanese student teachers in an online collaborative environment. This study built a Facebook Group and developed the tasks of collaborative learning based on field-experience courses. The participants were required to share various practical experiences as the collaborative learning tasks. A total of 100 student teachers who enrolled in field-based courses between August 2016 and January 2017 participated in this study and were required to complete a validated survey in January 2017. This study determined the relationships between the three learning styles and PAoCL and PKiT and further identified predictors of online collaborative learning. The collaborative learning style of student teachers was positively associated with their PAoCL, while competitive learning style was correlated with their PKiT. Accordingly, teacher educators can encourage student teachers to share experiences about teaching practices during participating in field-experience courses through online collaboration. However, teacher educators should remind the student teachers to transfer the online information into PKiT.
\end{abstract}

Keywords: online collaborative learning, learning style, student teacher, teaching practical knowledge

\section{Introduction}

In Taiwan, student teachers have to enroll in field-experience courses for six months. Ideally, a cooperating teacher with teaching experiences supports a student teacher. However, the teacher education system of Taiwan did not train experienced teachers to be cooperating teachers with mentoring competences, resulting in that student teachers did not necessarily have enough opportunities to obtain sufficient training as a teacher. Literature has indicated that cooperating teachers failed in finding an adequate combination of offering emotional support and task assistance for pre-service teachers (Crasborn, \& Hennissen, 2010), also lacked sufficient consulting competences (Rodgers, \& Keil, 2007), and seldom used emotional supports (Liu, 2014). The field-experience is a platform to bridge the theory and practice gap in initial teacher education (Coffey, 2010; Darling-Hammond, 2006). Student teachers are expected to obtain practical knowledge during practicum. When student teachers cannot experience sufficient teaching practices, they would encounter unanticipated obstacles in understanding teaching works.

Due to each student teacher could obtain a limited experience in his/her own practicing schools, online collaborative learning definitely provides an opportunity to allow student teachers from various schools around the country to share learning experiences during practicum (Clarke, 2009; Hou, 2015). Collaborative learning implies the constitution of groups of students who have a goal in common and organizes themselves to achieve a particular learning task. The students are challenged in the cognitive, social and emotional points of view by listening to others perspectives (Fawcett \& Garton, 2005; Persico, Pozzi, \& Sarti, 2010; Smith \& MacGregor, 1992). Online collaborative learning further allows students to exchange ideas and views beyond time and space constraints (Sorensen, 2004). Furthermore, online collaborative learning promotes the co-construction of knowledge (Okada, 2005) and helps student teachers in various schools engage in broader, more complex, and more cognitively challenging discussions.

Notably, studies have indicated that the learning styles of collaborative partners might affect peer interactions in collaborative learning activities (Adán-Coello, Tobar, Faria, Menezes, \& Freitas, 2011; Shaw, 2012). According 
to Kurilovas, Kubilinskiene, \& Dagiene (2014), "learning styles are strategies, or regular mental behaviors, habitually applied by an individual to learning, particularly deliberate educational learning, and built on her/his underlying potentials"(p.655). Some researchers have argued that whether learning style is a useful indicator of potential learning success because it provides information about individual differences in learning preferences and information-processing (Kolb \& Kolb, 2005; Smith \& Ragan, 1999).

Literature presented several learning style models. In term of online learning environment, VARK (visual, auditory, reading, and kinesthetic) learning styles are not suitable for measuring interactive performances of student teachers in collaborative learning because the VARK is composed of a combination of perception and memory on information.

According to Kolb (1984), learning process is a context of people moving between the modes of concrete experience and abstract conceptualization, and reflective observation and active experimentation. Kolb theorized that the four combinations of perceiving and processing determine one of the four learning styles of how people prefer to learn. Furthermore, Felder-Silverman (1988) referred to Kolb's learning styles and developed the model of learning styles, which was based on the notion that students have preferences in terms of the way they receive and process information. The model presents different dimensions, consisting of sensing/intuitive, visual/verbal, active/reflective, and sequential/global. The Felder-Silverman model was often used to measure students' learning style with hypermedia learning environment because the model focused on information inputting and processing in different ways based on students' individual preferences. However, the effectiveness of online collaborative learning involves the individual preferences on interactions among learners rather than on the information process in online multimedia. Thus, the Felder-Silverman's learning style models maybe are not able to indicate the effects on student teachers' performances in online collaborative learning environment. A study by Huang, Lin, \& Huang (2012) demonstrated the above perspective. Huang et al. investigated the effects of learning styles on learning participation by employing Felder-Silverman's learning style questionnaire and found that no significance exist.

Johnson \& Johnson (1994) defined three types of social interdependence from social interdependence theory, namely cooperative, competitive, and individualistic efforts. Cooperative efforts with positive interdependence result in promotive interaction, while competitive efforts with negative interdependence result in oppositional interaction, and furthermore, individualistic efforts with absence of interdependence result in no interaction. Social interdependence theory indicates that one's actions may promote the success of others, obstruct the success of others, or not have any effect at all on the success or failure of others (Johnson \& Johnson, 1994). Whenever people strive to achieve a learning goal, they may engage in cooperative, competitive, and individualistic efforts. The interaction patterns differentially affect learning performances. Accordingly, the three types of learning styles based on social interdependence theory may be useful supplements under certain conditions to investigate learners' performances in interactive learning environments. Balakrishnan and Gan (2016) found that students within cooperative perceptions have high self-efficacy perceptions than those who only thinking of and participating in the works.

The perceived advantages of online collaborative learning (PAoCL) among different levels of participation in online collaboration should be concerned. The PAoCL by students involves an individual perception regarding whether the interaction with peers is helpful for learning tasks. Hsieh, Jang, Hwang and Chen (2011) indicated that students could be benefited more if the received instructional strategies matched their learning styles. Chiong and Jovanovic (2012) found that active participants in online collaborative learning reported higher PAoCL than inactive ones. In other words, the learners with collaborative learning style would perceive more advantages on collaborative learning than those with competitive as well as individualistic style.

$\mathrm{Du}, \mathrm{Ge}$ and $\mathrm{Xu}$ (2015) examined the perspectives of African American female students toward online collaborative learning and found that the students preferred to work in a racially mixed group to advance their knowledge by learning from other groups' students. They have also perceived the benefit of learning in a collaborative group. However, they tended to engage in online collaborative activities for learning-oriented reasons rather than social or peer-oriented reasons. Gallien and Peterson (2004) indicated that African American students feel more comfortable when completing learning tasks that requires collaboration. Accordingly, the students with competitive learning style may affect their PAoCL.

In term of Taiwanese student teachers, to obtain practical knowledge in teaching (PKiT) is a vital goal during practicum. Through online collaborative learning, the student teachers can receive more information by experience-sharing and furthermore transfer the information to be their own PKiT. The experience-sharing belongs to collaborative rather than cooperative learning. Moreover, the student teachers need to participate in 
teacher recruitments and strive to perform PKiT in the recruitment exam after finishing field-experience courses. Competition among the student teachers in teacher recruitment exam is intense in Taiwan. Additionally, the student teachers have individual learning tasks that are evaluated by their cooperating teachers in practicum school. Accordingly, the student teachers need to simultaneously perform collaborative, cooperative and individualistic efforts on PKiT.

According to the above mentioned, three viewpoints facilitate the development of this study. 1). Taiwanese student teachers could obtain more information through online collaborative learning environment to transfer the information to their own practical knowledge. 2). The learning styles of the student teachers may affect their PAoCL and PKiT. 3). The learning styles involved in interaction and social interdependence include collaborative, competitive, and individualistic learning preferences. Based on the theoretical framework, indicating that student teachers' learning preferences (collaborative, competitive, and individualistic) maybe affect their PAoCL and PKiT, the purpose of this study is to investigate the effects of the three learning styles on the PAoCL and PKiT among Taiwanese student teachers in an online collaborative environment.

\section{Methodology}

\subsection{Research Design}

This study built a Facebook Group and developed the tasks of collaborative learning based on field-experience courses for Taiwanese student teachers. The participants were required to share various practical experiences as the collaborative learning tasks. The collaborative learning tasks, consisting of five questions, involve the practices of school administration, classroom management, lesson preparation, and teaching implementation and self-reflection. For example, a proposed question is "What obstacles have you encountered when you interact with children?" All members were required to respond at least once to any posting from others after being encouraged to practice critical thinking. Additionally, the participants were encouraged to propose their problems that happened in their practicum schools at any time.

Moreover, this study conducted a survey to investigate the effects of the three learning styles (collaborative, competitive, and individualistic) on the PAoCL and PKiT among Taiwanese student teachers.

\subsection{Participants}

This study recruited 100 student teachers who enrolled in field-based courses between August 2016 and January 2017 from a teacher education university in the middle of Taiwan. In addition to achieving the mentioned learning tasks, the student teachers were required to complete the survey in January 2017. In the study, 82 student teachers finished all learning tasks and filled in the questionnaire. Of the 82 participants, consisting of 21 male $(25.6 \%)$ and 61 female $(74.4 \%)$, they enrolled in practicum at junior high school $(37,45.1 \%)$, at senior high school $(26,31.7 \%)$, at vocational high school $(17,20.7 \%)$, and at special education school $(2,2.4 \%)$.

\subsection{Instruments}

The survey consists of baseline data and three questionnaires, namely learning style questionnaire (LSQ), the PAoCL questionnaire (PAoCLQ) and PKiT questionnaire (PKiTQ). The baseline data comprises gender and the types of practicum schools from which participants obtained field-based experiences (i.e., junior high school, senior high school, vocational school, or special education school). The three questionnaires, presenting with a 5-point Likert scale where 1 is "strongly disagree" and 5 is "strongly agree," were used to investigate the effects of learning styles on the PAoCL and PKiT among the student teachers during practicum.

\subsubsection{Learning style questionnaire}

The items of the LSQ were developed according to the definitions of collaborative, competitive, and individualistic learning preferences. The "collaborative learning style" is a learning preference regarding working together to accomplish shared goals. The "competitive learning style" refers to a preference with a social comparison with peers on learning performances. The "individualistic learning style" presents a learning preference that individuals work by themselves to accomplish goals. Each learning style, consisting of three items, reflects the different learning styles of student teachers regarding online collaborative learning. The participants presented their intensity of learning preferences in various facets of learning style items.

\subsubsection{Perceived advantages of online collaborative learning questionnaire}

The questionnaire of the PAoCLQ has seven items. The PAoCL refers to an individual perception that the online collaborative learning is useful for solving personal problems on teaching practices during practicum. Generally, all Taiwanese student teachers should be assessed in the final month of the field-experience course according to Index of Educational Practice Assessment (IEPA) regulated by Ministry of Education (https://ws.moe.edu.tw/ 
001/Upload/1/relfile/7537/25921/0e147cfe-47a2-4a73-9e07-02c9eb668bcf.pdf). The items of the PAoCLQ refer to the IEPA and adopt the seven core performances of teaching practices in IEPA, consisting of teaching objects, lesson plan, instructional material design, teaching activities, teaching skills, learning assessment, and reflection on teaching practices. Each core performance was developed as an item. An example item on PAoCLQ is "The online collaborative learning program is useful for me to [make...]."

\subsubsection{Teaching practical knowledge questionnaire}

The questionnaire of the PKiTQ has six items. The items refer to a study by Pan, Chang and Zang (2008) who constructed the evaluative/professional standards for Taiwan elementary and junior high school teachers. This study analyzed those standards and categorized six kinds of teaching practical knowledge involving PKiT, i.e., subject content knowledge, pedagogical content knowledge, pedagogical knowledge, instructional skill knowledge, knowledge of assessment, and knowledge of learners and their characteristics. The importance here is not to name an exhaustive set of knowledge based, but to recognize the kinds of knowledge, called knowledge for practice, that are obtained by student teachers during practicum. Each category of knowledge was developed as an item. An example item on PKiTQ is "Through participating in the online collaborative learning program, I have understood [how... according to...]."

\subsubsection{Validity and reliability of the three questionnaires}

The LSQ, consisting of three facets (collaborative, competitive, and individualistic), were validated according to the results of the item analysis $(t$ values $=8.140-12.890, p<.05)$. The calculated results of item-total score correlations revealed that coefficients of $r$ value were 0.737-0.896 $(p<.05)$. A factor construct through a principal component factor analysis showed KMO coefficient $(0.658-0.729)$ and Bartlett test $(p<.001)$. The Cronbach alpha coefficients were $0.807,0.687$, and 0.846 , with the total coefficient 0.800 . The loadings of the factors in nine items exceeded 0.6.

For the PAoCLQ with seven items, the results of the item analysis revealed that $t$ values ranged from 7.162$9.249(p<.05)$. The $r$ values of the items ranged from $0.680-0.853(p<.05)$. A factor analysis with a varimax rotation was performed to clarify its structure. The KMO coefficient was 0.848 and the $p$ value for the Bartlett test was less than 0.001 . Only one factor was emerged with eigenvalues $>1$ and accounted for $60.345 \%$ of variance, with responses with loadings of 0.661-0.865 on the PAoCLQ. The Cronbach alpha coefficient for the PAoCLQs was 0.888 .

The calculated results of the items in the PKiTQ revealed that $t$ values ranged from 5.225-10.457 $(p<.05)$. The $r$ values of the items ranged from $0.658-0.805(p<.05)$. As the same as the PAQs' factor analysis, the KMO coefficient was 0.813 and the $p$ value for the Bartlett test was less than 0.001 . Only one factor was emerged with eigenvalues $>1$ and accounted for $50.818 \%$ of variance, with responses with loadings of $0.648-0.806$ on the PKiTQ. The Cronbach alpha coefficient for the PKiTQs was 0.805 .

\subsection{Data analysis}

First, independent sample $t$ tests were conducted to determine whether the gender of participants affected the factors in this study; however, the analytical results revealed nonsignificant differences $(t$ value $=-0.509$ to $-0.607, p>.05$ ). Additionally, a one-way analysis of variance was calculated to determine whether the practicum schools of the student teachers exerted dissimilar influences between the variables. The analytical results determined nonsignificant variations among the various practicum schools $(F$ value $=1.052$ to $1.251, p>0.05)$. These results eliminated the possibility of gender and practicum school types affecting any of the factors in this study.

Afterward, data were analyzed using multiple regression technique to investigate the effects of the three learning styles on PAoCL as well as PKiT among the student teachers.

\section{Results}

Table 1 shows the descriptive statistics of the three learning styles, the PAoCL and the PKiT of the student teachers that are above average. Table 2 shows the relationships between the three learning styles, the PAoCL, and the PKiT. Analytical result shows that all learning styles were positively associated with PAoCL as well as $\operatorname{PKiT}(p=0.000<0.05)$.

Moreover, a colinearity analysis was performed to avoid the unexplained contradiction among the coefficients in multiple regression analysis. When the tolerance value (TOL) exceeds 0.10 , the variance inflation factor (VIF) is less than 10, the condition index $(\mathrm{CI})$ is less than 30 and the eigenvalue is more than 0.01 , the multi-collinearity problem does not exist for independent variables. The analytical results of this study showed that TOL $(>0.10)$, 
$\operatorname{VIF}(1.499,1.576,1.095,<10), \mathrm{CI}(8.045 \sim 20.872,<30)$ and the eigenvalue $(0.61,0.12,0.11,>0.1)$ values fit the above indicators, meaning that multi-collinearity problem did not exist for independent variables.

Table 1. The descriptive statistics of the three variables related to online collaboration

\begin{tabular}{cccccc}
\hline & Variable & \multirow{2}{*}{$\mathrm{M}$} & $\mathrm{SD}$ & \multicolumn{2}{c}{ 95\% Confidence Interval } \\
\cline { 5 - 6 } & & & 1.81 & Lower ( LL) & Upper (UL) \\
\hline \multirow{2}{*}{ Learning } & Collaborative & 4.13 & & 4.00 & 4.27 \\
Style & Competitive & 4.02 & 1.88 & 3.88 & 4.15 \\
& Individualistic & 2.96 & 2.74 & 2.76 & 3.16 \\
& PAoCL & 3.90 & 4.42 & 3.76 & 4.03 \\
& PKiT & 3.72 & 3.63 & 3.59 & 3.85 \\
\hline
\end{tabular}

Table 2 Summary of Pearson correlation analysis of the three factors

\begin{tabular}{cccc}
\hline & & Learning Style & \\
\cline { 2 - 4 } & Collaborative & Competitive & Individualistic \\
\hline PAoCL & $.556^{*}$ & $.371^{*}$ & $.267^{*}$ \\
PKiT & $.235^{*}$ & $.367^{*}$ & $.249^{*}$ \\
\hline${ }^{*} p<.05$ & & &
\end{tabular}

Furthermore, multiple regression analysis was utilized to investigate whether the three learning styles could predict PAoCL and PKiT. Table 3 lists the calculated results from multiple regression analysis.

Table 3. Summary of multiple regression analysis

\begin{tabular}{cccccccc}
\hline Dependent variable & Independent variable & $\mathrm{B}$ & $\beta$ & $t$ & $p$ & $R^{2}$ & $F$ \\
\hline \multirow{3}{*}{ PAoCL } & Collaborative & 1.234 & 0.506 & 4.476 & $\mathbf{. 0 0 0}$ & & \\
& Competitive & 0.077 & 0.033 & 0.284 & .777 & .310 & $13.124^{*}$ \\
& Individual & 0.254 & 0.158 & 1.634 & .106 & & \\
\hline \multirow{3}{*}{ PKiT } & Collaborative & 0.059 & 0.029 & 0.230 & .819 & & \\
& Competitive & 0.588 & 0.305 & 2.338 & $\mathbf{. 0 2 2}$ & .125 & $4.856^{*}$ \\
& Individual & 0.204 & 0.154 & 1.418 & .160 & & \\
\hline
\end{tabular}

${ }^{*} p<.05$

In terms of PAoCL, Table 3 shows that $F$ value was significant $(F=13.124, p<.05)$, meaning that the three learning styles contributed significantly to explaining the PAoCL. The proportion of variance explained by the regression model was reflected by adjusted $R^{2}$ values of $31.0 \%$. Similarly, the three learning styles also contributed significantly to explaining the PKiT $(F=4.856, p<.05)$. The proportion of variance explained by the regression model was $12.5 \%$ from adjusted $R^{2}$ values.

The $\beta$ coefficients are standardized weights indicating the relative importance of independent variables. According to the $\beta$ coefficients acquired with the multiple regression model, collaborative learning style explained PAoCL most ( $\beta=0.506$ ), meaning that the collaborative learning style had a positive effect on PAoCL. Additionally, competitive learning style explained PKiT most ( $\beta=0.305)$, meaning that the competitive learning style also had a positive effect on PKiT.

Thus, these findings indicate that the student teachers with collaborative learning preference would have better PAoCL than those who student teachers with competitive as well as individualistic learning style. Additionally, the student teachers with competitive learning preference would have better PKiT than those who student teachers with collaborative as well as individualistic learning style.

\section{Conclusions and Discussion}

This study determined the relationships between the three learning styles and PAoCL and PKiT and further identified predictors of online collaborative learning. The collaborative learning style of student teachers was positively associated with their PAoCL, while competitive learning style was correlated with their PKiT.

Based on the required learning tasks in this study, the student teachers shared practical experiences from their 
own practicum school to other members in online collaborative learning group. Meanwhile, they received the similar information from other members. The student teachers with collaborative learning preference were willing to exchange ideas, views, and even barriers through online interaction. The above information could provide the opportunities for the student teachers to re-examine their own instructional practices. Thus, the student teachers perceived that the above information was useful on teaching objects, lesson plan, instructional material design, teaching activities, teaching skills, learning assessment, and reflection on teaching practices. As the studies by Hsieh, et al. (2011) and Chiong, et al. (2012), the student teachers with collaborative learning style have perceived the advantages of sufficient information for their practicum. However, the student teachers with competitive leaning style and negative interdependence, did not perceive the usefulness of information sharing, resulting in oppositional interaction. Additionally, the student teachers with individualistic leaning style may lack interaction with group members, resulting in that they could not perceive the advantages of information sharing during online collaborative learning.

Moreover, in terms of PKiT, the student teachers must transfer the obtained information from the collaborative learning activities into their own practical knowledge, including subject content knowledge, pedagogical content knowledge, pedagogical knowledge, instructional strategic knowledge, knowledge of assessment, and knowledge of learners and their characteristics. According to collaborative learning viewpoints, online collaborative learning only provides the opportunities for the co-construction of knowledge, rather than constructs each person's practical knowledge. The student teachers with collaborative learning style easily perceived the interactive situation, while the student teachers with competitive learning style might be concerned about practical knowledge transformation. Thus, the student teachers with competitive learning style have strong perceptions of PKiT. As for the student teachers with individualistic learning style, they preferred to individualistic efforts. When the student teachers were not willing to interact with other members, they did not obtain sufficient information regarding teaching practices. In addition to lack of PAoCL, the student teachers with individualistic learning style failed to transfer the practical information into PKiT because of lack of sufficient information, resulting in less PKiT.

In Taiwan, student teachers always expect themselves to obtain sufficient practical knowledge and by that, further pass the exam of teacher recruitment under competition in the future. This is why the competitive learning style of the student teachers cannot predict their PAoCL, but predict their PKiT. Even though the student teachers with competitive learning style participated in peer-interaction, they were more concerned about practical knowledge transformation, resulting in strong perceptions of PKiT.

The performances of the student teachers are similar to those African American students in the study by Du, et al. (2015), showing that they maybe engage in collaborative learning activities only to advance their teaching knowledge by learning from peer groups. The collaboration provided the opportunities for the student teachers from various practicum schools around the country to engage in broader, more complex, and more cognitively challenging discussions. The student teachers with collaborative learning style could obtain sufficient learning opportunities. However, the student teachers with competitive learning style may participate in peer-interaction but they mainly construct their PKiT.

\section{Implications and limitation}

Online Collaborative leaning can improve the disadvantages of current field-experience courses. However, different learning styles partly related to PAoCL and PKiT of student teachers. Thus, teacher educators can encourage student teachers to share experiences about teaching practices during participating in field-experience courses through online collaboration. However, teacher educators should remind the student teachers to transfer the online information into PKiT.

This study found that the competitive learning style of the student teachers predicted their PKiT in the collaborative learning environment. Further research could determine whether the interactive frequency of collaborative learning is the mediated variable between competitive learning style of student teachers and their PKiT.

There is a limitation of this study. Each student does not necessarily only demonstrate a learning style. Learning style refers to learning preference. This study only focuses on whether different learning preference of the student teachers participating in online collaborative learning can predict their learning performances, rather than identifies which learning style of each participant is the most apparent among learning styles.

\section{Acknowledgments}

The research is financed by Ministry of Science and Technology, Taiwan. No. MOST-104-2410-H-018-013-SSS- 


\section{References}

Adán-Coello, J. M., Tobar, C. M., Faria E. S. J., Menezes, W. S, \& Freitas, R. L. (2011). Forming groups for collaborative learning of introductory computer programming based on students' programming skills and learning styles. International Journal of Information and Communication Technology Education, 7(4), 34-46. https://doi.org/10.4018/jicte.2011100104

Liu, S.-H. (2014). Excellent mentor teachers'skills in mentoring for pre-service teachers. International Journal of Education, 6(3), 29-42. https://doi.org/10.5296/ije.v6i3.5855

Balakrishnan, V., \& Gan, C. L. (2016). Students' learning styles and their effects on the use of social media technology for learning. Telematics \& Informatics, $33(3), \quad 808-821$. https://doi.org/10.1016/j.tele.2015.12.004

Chiong, R. \& Jovanovic, J. (2012). Collaborative learning in online study groups: An evolutionary game theory perspective. Journal of Information Technology Education, 11, 81-101.

Clarke, L. (2009). The POD model: using communities of practice theory to conceptualize student teachers' professional learning online. Computers \& Education, 52(3), 521-529. https://doi.org/10.1016/j.compedu.2008.10.006

Coffey, H. (2010). "They taught me": The benefits of early community-based field experiences in teacher education. Teaching and Teacher Education, 26(2), 335-342. http://dx.doi.org/10.1016/j.tate.2009.09.014

Crasborn, F., \& Hennissen, P. (2010). The skilled mentor: Mentor teachers' use and acquisition of supervisory skills. Eindhoven: Eindhoven School of Education.

Darling-Hammond, L. (2006). Powerful teacher education: Lesson for exemplary programs. San Francisco: Jossey-Bass.

Du, J., Ge, X., \& Xu, J. (2015). Online collaborative learning activities: The perspectives of African American female students. Computers \& Education, 82, 152-161. https://doi.org/10.1016/j.compedu.2014.11.014

Fawcett, L. M., \& Garton, A. F. (2005). The effect of peer collaboration on children's problem-solving ability. British Journal of Educational Psychology, 75, 157-169. https://doi.org/10.1348/000709904X23411

Felder, R. M., \& Silverman, L. K. (1988). Learning styles and teaching strategies in engineering education, Engineering Education, 78, 674-681

Gallien, L. B., Jr., \& Peterson, M. S. (2004). Instructing and mentoring the African American College student: Strategies for success in higher education. Boston, MA: Allyn and Bacon.

Hou, H. (2015). What makes an online community of practice work? A situated study of Chinese student teachers' perceptions of online professional learning. Teaching and Teacher Education, 46, 6-16. https://doi.org/10.1016/j.tate.2014.10.005

Hsieh, S. W., Jang, Y. R., Hwang, G. J., \& Chen, N. S. (2011). Effects of teaching and learning styles on students' reflection levels for ubiquitous learning. Computer \& Education, 57(1), 1194-1201. https://doi.org/10.1016/j.tate.2014.10.005

Huang, E. Y., Lin, S. W., \& Huang, T. K. (2012). What type of learning style leads to online participation in the mixed-mode e-learning environment? A study of software usage instruction. Computers \& Education, 58(1), 338-349. https://doi.org/10.1016/j.compedu.2011.08.003

Johnson, D. W. \& Johnson, R. T. (1994). Learning together and alone: Cooperative, competitive, and individualistic learning. Boston: Ally \&Bacon.

Kolb, D. (1984). Experiential learning: experience as the source of learning and development. Englewood Cliffs, New Jersey: Prentice Hall.

Kolb, A. Y., \& Kolb, D. A. (2005). Learning styles and learning spaces: enhancing experiential learning in higher education. Academy of Management Learning \& Education, 4(2), $193-212$. https://doi.org/10.5465/AMLE.2005.17268566

Kurilovas, E., Kubilinskiene, S., \& Dagiene, V. (2014). Web 3.0-Based personalization of learning objects in virtual learning environments. Computers in Human Behavior, 30, 654-662. https://doi.org/10.1016/j.chb.2013.07.039

Okada, A. (2005). The collective building in collaborative learning environments. In T. S. Roberts (Ed.). Computer-supported collaborative learning in higher education (pp. 70-99). Hershey, PA: Idea Group 
Publishing. https://doi.org/10.4018/978-1-59140-408-8.ch004

Pan, H. L., Chang, D., \& Zang, X. R. (2008). The construction of the evaluative/professional standards for Taiwan elementary and junior high school teachers: The processes. In H. L. Pan (Ed.), Teacher evaluation: Theories and practices (pp. 229-280). Taipei, Taiwan: Center for Educational Research and Evaluation, NTNU.

Persico, D., Pozzi, F., \& Sarti, L. (2010). Monitoring collaborative activities in computer supported collaborative learning. Distance Education, 31(1), 5-22. https://doi.org/10.1080/01587911003724603

Rodgers, A. \& Keil, V. (2007). Restructuring a traditional student teacher supervision model: Fostering enhanced professional development and mentoring within a professional development school context. Teaching and Teacher Education, 23(1), 63-80. http://dx.doi.org/10.1016/j.tate.2006.04.012

Shaw, R.-S. (2012). A study of the relationships among learning styles, participation types, and performance in programming language learning supported by online forums. Computers \& Education, 58, 11-120. https://doi.org/10.1016/j.compedu.2011.08.013

Sorensen, E. K. (2004). Reflection and intellectual amplification in online communities of collaborative learning. In T. S. Roberts (Ed.). Online collaborative learning: Theory and practice (pp. 242-261). Hershey, PA.: Information Science Publishing. https://doi.org/10.4018/978-1-59140-174-2.ch011

Smith, L., \& MacGregor, J. (1992).What is collaborative learning? In A. Goodsell, et al (1992). Collaborative learning: A sourcebook for higher education (pp. 1-11). Pennsylvania: National Center on Postsecondary Teaching, Learning, and Assessment.

Smith, P. L., \& Ragan, T. J. (1999). Instructional design (2nd). USA: John Wiley\& Sons, Inc.

\section{Copyrights}

Copyright for this article is retained by the author(s), with first publication rights granted to the journal.

This is an open-access article distributed under the terms and conditions of the Creative Commons Attribution license (http://creativecommons.org/licenses/by/4.0/). 